FRANK CRAWLEY, F.R.C.S.I.

WE regret to record the sudden death in Dublin on December 15 , 1935, of Mr. Crawley. Born in Dublin in 1871, he was the son of the late W. J. Chetwode Crawley, LL.D., D.C.L. After preliminary education in Ireland he entered Shrewsbury School in 1886, where he was in School House under Moss. He left in the next year for Caius College, Cambridge, and took his B.A. in 1892. Crawley qualified M.B., B.Ch. at Dublin in 1896, and later took the M.D., becoming F.R.C.S.I. in 1900. After postgraduate study in Berlin and Vienna he returned to Dublin and was elected surgeon to the Royal Victoria Eye and Ear Hospital. Later he became ophthalmic surgeon to the City of Dublin Hospital, and consulting ophthalmic surgeon at the Rotunda.

Crawley served as President of the Royal College of Surgeons in Ireland from 1932-1934, and he was president of the section of ophthalmology of the British Medical Association at the Dublin meeting three years ago. He became a member of the Ophthalmological Society of the United Kingdom in 1901, and contributed a large number of papers to its Transactions. These were nearly all of purely clinical character and cover a wide field, as befitted a first-class ophthalmic surgeon, whose reputation, both in his own island and in Great Britain, was deservedly high.

His death is a severe blow to British ophthalmology.

\title{
PROFESSOR RICHARD DEUTSCHMANN
}

WE regret to record the death of this veteran German ophthalmologist on November 13, 1935, at the great age of 83 years. The following appreciation is epitomised from an account kindly furnished by Professor W. Gilbert, of Hamburg, to whom we are greatly indebted.

Notwithstanding severe bodily suffering, Dr. Deutschmann was at work until a few days before his death. He was born in 1852 in Silesia and began the study of ophthalmology at Göttingen as a pupil of Leber. After further study in London and Paris he settled in Hamburg and quickly made a great reputation both on the Continent and in this country as a sound ophthalmologist. Much of his early published work was on the subject of sympathetic ophthalmitis, and he was honoured by the German Ophthalmological Society in 1889 when he received the Graefe prize for his essay.

It is interesting to recall that Deutschmann was among the first to refuse to believe that retinal detachment was an incurable disease. At a time when almost every other ophthalmic surgeon considered retinal detachment a hopeless condition, Deutschmann 